\title{
Dependency of BET surface area on particle size for some granitic minerals
}

\author{
By I. E. Dubois ${ }^{1,2, *}$, S. Holgersson ${ }^{2}$, S. Allard ${ }^{2}$ and M. E. Malmström ${ }^{1}$ \\ ${ }^{1}$ Industrial Ecology, Royal Institute of Technology (KTH), 10044 Stockholm, Sweden \\ 2 Nuclear Chemistry, Chalmers University of Technology, 41296 Gothenburg, Sweden
}

(Received December 22, 2009; accepted in final form November 11, 2010)

\section{Surface area / Particle size / Radionuclide / Magnetite / Plagioclase}

\begin{abstract}
Summary. In order to assess the geochemical retention properties of rocks, which will be the final barrier for radionuclide transport to the biosphere in the case of a failed deep underground repository for spent nuclear fuel, radionuclide sorption experiments are usually made with crushed material. This raises the issue of extrapolating results obtained from laboratory experiments to the field scale. As sorption is generally related to the surface area of the geological material, it is then important to consider the dependency of the specific surface area on the particle size. In this work, BET surface area determinations of samples of different particle sizes are conducted on two minerals commonly found in granite: labradorite and magnetite. The results show a linear relationship between BET surface area and the inverse of the particle size, up to a certain particle size. Furthermore, results also show that the specific surface area for intact, larger pieces is much smaller than the one predicted by a linear extrapolation of results on crushed material. Therefore, extrapolation of BET area for fine particles to the field situation will lead to an overestimation of the surface area and thereby also the radionuclide sorption, if sorption coefficients are extrapolated as well. Also of importance is that these results show that sorption experiments on crushed material may dominantly reflect properties of new surface, created during the mechanically treatment of the samples.
\end{abstract}

\section{Introduction}

Nuclear power is an important source of energy for the production of electricity in many countries around the world and causes less greenhouse gas emissions than fossil fuel based energy sources [1,2]. However, the handling of the spent nuclear fuel remains an important issue. One solution is the storage of the waste in a deep underground repository, either with or without reprocessing (separation, transmutation).In a worst-case scenario of a failed underground repository, the host rock would be the last barrier to prevent the transport of radionuclides to the biosphere. For safety assessment of a final repository, it is therefore essential to estimate the retention properties of the host rock. The sorption of radionuclides

\footnotetext{
*Author for correspondence (E-mail: idubois@kth.se).
}

on the rock material, which contributes to geochemical retention, is commonly determined in small-scale experiments in laboratory, using crushed material. A problem with this method is on how to extrapolate the results of the laboratory experiments to the field situation.

A linear correlation of the surface area with the distribution coefficient for radionuclide sorption, $R_{\mathrm{d}}\left(\mathrm{m}^{3} / \mathrm{kg}\right)$, for particular geological material of different size fractions of crushed material in laboratory experiments have been observed in several studies (granitic sand: [3]; granitic rock: $[4,5])$. Here, it should be noted that whereas surface area determinations using the BET method (acronym for Brunauer-Emmet-Teller, who first developed the method [6]) relies on sorption of a multilayer of gas molecules onto the entire physical surface, the sorption of radionuclides through surface complexation and/or ion exchange mechanisms involves the attachment of the radionuclide to specific sites at the surfaces. From theory, a linear relation between $R_{\mathrm{d}}$ and the BET surface area would be expected for, for example, isotropic materials with an even distribution of evenly reactive sites over all exposed physical surfaces. For anisotropic materials, or materials with different reactive sites, a linear correlation can be expected, if the relative abundance of faces and sites between the samples of different specific surface area equal.

Based on the experimentally observed linear relation between $R_{\mathrm{d}}$ and $\mathrm{BET}$, it has been proposed that the specific surface area can be used to predict $R_{\mathrm{d}}$ values for any size fraction of the material, even including the intact material. Already Skagius et al. [7] proposed that the particle size dependency of the sorption of Cs and Sr onto crushed granite in the size fraction range of $0.1-1.5 \mathrm{~mm}$, which they observed, could be explained by sorption onto an inner and an external surface area, where the external surface area is proportional to the inverse of the particle size. The data of Byegård et al. [4], however, shows that the linear relationship between the $R_{\mathrm{d}}$ value and the BET specific surface area of granitic rock is not necessarily valid when a wider particle range $(0.045-4 \mathrm{~mm})$ is studied, which may, for example, reflect different surface properties of the size fractions.

When a rock sample is drilled out of the host rock and crushed and sieved to a given size fraction, many of these operations can alter the rock's surface properties. In the natural rock environment, the material is under high pressure 
due to the weight of the surrounding rock. When a drill core sample is taken out of the rock matrix, the release from this pressure allows the opening of small fractures, thereby increasing the microporosity and the internal surface (see summary in [8]). The process of drilling and sawing may itself damage the outermost layer of the drill core creating a disturbed zone, up to centimeter thick in the sampled material $[9,10]$. New surfaces, not previously exposed, are also created during the crushing process. The internal and external area increase, and the fresh surfaces exposed during these processes can have different surface properties than the intrinsic surfaces. All these effects may have considerable influence on the sample surface properties, which in turn may affect radionuclide sorption.

An effect of the damaged zone on the BET surface area can be observed up to a certain particle size in granite [8]. By the use of centimeter-sized or larger pieces of material in laboratory studies, experimental results that are not dominated by the properties of the disturbed zone can be obtained. However, also for such large samples, the issue of the release of the rock load remains. Establishing a relationship between particle size and the specific surface area is one essential tool for understanding the studied system and it may also be a help for understanding sorption onto intact material.

The relationship between particle size and specific surface area has previously been studied by several authors. Bradbury and Baeyens [11] compared centimeter pieces with crushed material of particle size less than $63 \mu \mathrm{m}$. They found that for clay minerals (illite, zeolite), bentonite and a few sedimentary rock samples; the specific surface areas were similar between the large piece and the crushed material for each mineral or rock sample. However, for calcite, orthoclase and a crystalline rock sample (granodiorite), the surface area of the crushed material was a factor 7-19 times larger than for the large piece of the same material.

André et al. [8] observed that the dependency of the surface area on the inverse of the particle size is linear for small particles of granite, which is also consistent with the experimental results of Byegård et al. [4]. For larger pieces, the specific surface area appeared to be considerably smaller than expected from this linear trend $[4,8]$. A similar behavior was observed for sanidine (a K-feldspar) and chlorite [12]. This was interpreted as a disturbed zone dominating the properties of the material below a certain particle size [13]. As the size increases, the disturbed zone no longer dominates and this yields a lower specific surface area. The aim of this work is to establish a relationship between specific surface area and particle size for two minerals commonly found in granitic rock, labradorite and magnetite. This helps evaluating the extrapolation of sorption coefficients from laboratory scale experiments to the field scale. Specific surface areas for different size fractions of the minerals are determined by gas adsorption, interpreted through the BET [6] model.

\section{Theory}

A theory for the particle size dependency of the specific surface area of granitic rocks and minerals is described by
André et al. [8]. For simplicity, particles were assumed to be spherical, with an external and internal surface area following the suggestion by Skagius et al. [7]. Starting from a simple model for perfectly smooth particles, the external specific surface area $\left(\mathrm{SSA}_{\mathrm{ext}}\right.$, in $\left.\mathrm{m}^{2} \mathrm{~g}^{-1}\right)$ can be expressed as follows, from the area and volume of the particle (see [7] for details):

$$
\mathrm{SSA}_{\mathrm{ext}}=\frac{4 \pi R^{2}}{\frac{4}{3} \rho \pi R^{2}}=\frac{3}{\rho R},
$$

where $R[\mathrm{~m}]$ is the radius of the spherical particle and $\rho$ $\left[\mathrm{g} \mathrm{m}^{-3}\right]$ is the density of the material. Deviations from the perfectly smooth particles are introduced via a roughness factor, $\lambda$ [unitless], expressed as follow:

$$
\lambda=\frac{\mathrm{SSA}_{\text {real }}}{\mathrm{SSA}_{\text {ideal }}},
$$

where $\mathrm{SSA}_{\text {real }}$ is the real, external specific surface area of a rough particle and $\mathrm{SSA}_{\text {ideal }}$ is the external, specific surface area of the ideal, smooth particle. Assuming a rectangular distribution of particle sizes between the lower and upper sieve cutoffs, $2 R_{1}$ and $2 R_{2}$, the representative particle radius is given by (see [8]):

$$
R_{\mathrm{REP}}^{-1}=\frac{4\left(R_{2}^{3}-R_{1}^{3}\right)}{3\left(R_{2}^{4}-R_{1}^{4}\right)} .
$$

The internal specific surface area $\left(\mathrm{SSA}_{\text {int }}\right)$ is assumed to be proportional to the volume of the sample, but independent of the particle size, as follows:

$$
S S A_{\text {int }}=\frac{a_{\mathrm{r}}}{\rho},
$$

where $a_{\mathrm{r}}\left[\mathrm{m}^{2} \mathrm{~m}^{-3}\right]$ is the internal surface area per rock volume. The mechanical processing of the rock, drilling and sawing, creates a millimeter to centimeter thick disturbed zone in the rock. The increase in porosity comes along with an increase in the internal specific surface area of this disturbed zone. The crushing down to a certain particle size implies that part of or the entire volume of the particles consists of a disturbed zone. Thus, extrapolation to the intact rock would include surfaces naturally present as well as surfaces created by the mechanical processing. This would result in an overestimation of the specific surface area for intact material.

To account for this disturbed zone, the model was modified to account for an additional internal surface area, $a_{\text {dist }}$ $\left[\mathrm{m}^{2} \mathrm{~m}^{-3}\right]$, associated with the mechanically created micro cracks within a disturbed zone of thickness $\delta$ [m] [8]. For simplicity $a_{\text {dist }}$ was assumed to be constant throughout the disturbed zone. After simplification, the specific surface area for the disturbed zone $\left(\mathrm{SSA}_{\mathrm{DZ}}\right)$ was expressed as [8]:

$$
\mathrm{SSA}_{\mathrm{DZ}}=\frac{a_{\mathrm{dist}}}{\rho} \quad \text { for } R \leq \delta
$$

for particles smaller than the disturbed zone, and as

$$
\mathrm{SSA}_{\mathrm{DZ}}=\frac{a_{\mathrm{dist}}\left(3 R^{2} \delta-3 R \delta^{2}+\delta^{2}\right)}{\rho R^{2}} \quad \text { for } R>\delta
$$


for particles larger than the disturbed zone, that is, particles that contain a mechanically undisturbed core.

Experimentally, all areas are determined simultaneously

$$
\mathrm{SSA}_{\mathrm{tot}}=\mathrm{SSA}_{\mathrm{ext}}+\mathrm{SSA}_{\mathrm{int}}+\mathrm{SSA}_{\mathrm{DZ}}
$$

For small particles $(R \leq \delta)$ a linear relationship between the specific surface area and the inverse of the particle size is expected

$$
\mathrm{SSA}_{\mathrm{tot}}=\frac{3 \lambda}{\rho R}+\frac{a_{\mathrm{r}}}{\rho}+\frac{a_{\mathrm{dist}}}{\rho} \quad \text { for } R \leq \delta .
$$

However, for larger particles $(R>\delta)$ a negative deviation from this linear relationship is expected through

$$
\mathrm{SSA}_{\mathrm{tot}}=\frac{3 \lambda}{\rho R}+\frac{a_{\mathrm{r}}}{\rho}+\frac{a_{\mathrm{dist}}\left(3 R^{2} \delta-3 R \delta^{2}+\delta^{3}\right)}{\rho R^{3}} \text { for } R>\delta .
$$

Deviation from spherical or cubic form of the particle primarily affects the first term of Eq. (6) and would in our case be lumped into $\lambda$ in the first term, and would also affect the third term in Eq. (6c) (see Dubois et al. [12]). We note that for particles of rectangular cuboid form, a thin particle would increase the apparent $\lambda$; with the apparent $\lambda$ being derived from the slope of the straight line as obtained from plotting the surface area against the inverse of the particle size, assuming spherical or cuboid form of the particles (term 1 in Eq. (6c)). On the opposite, a thick particle would decrease it. In this work, Eq. (6b) is used for extrapolation of specific surface areas to large particles, more similar to the field situation. In this, $\lambda$ and $\left(a_{\mathrm{r}}+a_{\text {dist }}\right)$ are fitting parameters, using $\rho \mathrm{SSA}_{\text {tot }}$ as the independent variable, with $\rho$ and $\mathrm{SSA}_{\text {tot }}$ being experimentally determined. For large particles, the first and third terms of Eq. (6c) are small; therefore $\rho \mathrm{SSA}_{\text {tot }}$ approximates $a_{\mathrm{r}}$.

\section{Material}

The minerals studied here typically occur in granitic material. The rock material from the Äspö site is taken as a reference for mineral composition of granite. The Äspö Hard Rock Laboratory is a demonstration and research facility for a final repository for radioactive waste, on the east coast of Sweden [14]. The two minerals studied here are labradorite, a tectosilicate from the feldspar group, and magnetite, an iron oxide. Labradorite belongs to the plagioclase undergroup, which in turn belongs to the sodium/calcium feldspar group. This group contains important rock-forming minerals, which make about $60 \%$ of the Earth's crust, commonly found in rocks, sediments and soils [15]. It represents $\sim 13 \%$ of the Äspö material and additionally $\sim 13.2 \%$ as aged plagioclase [16]. All minerals that have a composition varying between the sodium end-member albite $\left(\mathrm{NaAlSi}_{3} \mathrm{O}_{8}\right)$ and the calcium end-member anorthite $\left(\mathrm{CaAl}_{2} \mathrm{Si}_{2} \mathrm{O}_{8}\right)$ are included in this undergroup. Labradorite is an intermediate mineral, with 50 to $70 \%$ calcium.

Magnetite is a mixed valence iron oxide, where iron is present in two oxidation states, ferrous and ferric iron, with the general formula $\mathrm{Fe}_{3} \mathrm{O}_{4}\left(\mathrm{Fe}^{3+}\left[\mathrm{Fe}^{2+} \mathrm{Fe}^{3+}\right] \mathrm{O}_{4}\right)$. It is a common mineral in igneous rocks, such as granite, and has been
Table 1. Chemical composition [wt $\%]$ and density $\rho\left[\mathrm{kg} \mathrm{m}^{-3}\right]$ for magnetite and labradorite.

\begin{tabular}{lccc}
\hline Element [\%] & Magnetite & Labradorite & Uncertainty \% \\
\hline $\mathrm{SiO}_{2}$ & 0.797 & 53.4 & 19 \\
$\mathrm{Al}_{2} \mathrm{O}_{3}$ & 0.194 & 25.3 & 17 \\
$\mathrm{CaO}$ & $<0.1$ & 10.2 & 11 \\
$\mathrm{Fe}_{2} \mathrm{O}_{3}$ & 97.9 & 3.41 & 11 \\
$\mathrm{~K}_{2} \mathrm{O}$ & 0.152 & 0.504 & 9 \\
$\mathrm{NaO}$ & $<0.05$ & 3.26 & 12 \\
$\mathrm{MgO}$ & 0.447 & 2.45 & 13 \\
$\mathrm{C}$ & $<0.1$ & $<0.2$ & 9 \\
$\mathrm{~S}$ & $<0.001$ & $<0.01$ & 8 \\
$\rho\left(\mathrm{kg} \mathrm{m}^{-3}\right)$ & $4.85 \times 10^{3}$ & $2.70 \times 10^{3}$ & 10 \\
\hline
\end{tabular}

often studied for its sorption capacity (see [17-20] amongst others). Opaque minerals, consisting mostly of magnetite, represent $0.6 \%$ of the Äspö rock material [16].

The minerals used here are natural minerals. The labradorite comes from Madagascar, and the magnetite from Kiruna, in the north part of Sweden. Density measurements were made by weighing a sample of dry mineral and the amount of water displaced by the same sample.

The chemical composition of the materials used in this study was determined by ALS Scandinavia AB, Luleå, Sweden, by dissolution either in $\mathrm{HNO}_{3}$ in a microwave oven in an enclosed Teflon container or in a $\mathrm{LiBO}_{2}$ melt followed by dissolution in $\mathrm{HNO}_{3}$. Elemental analyses of the resulting solution were performed by Inductive Coupled Plasma - Atomic Electron Spectroscopy, - Quadrupole Mass Spectrometry or - Sector Mass Spectroscopy (ICP-AES, -QMS or-SMS). Additional determinations were made for sulfur through dissolution in $\mathrm{HF}, \mathrm{HClO}_{3}$, and $\mathrm{HNO}_{3}$ with heating followed by analyses of the solution with ICP-OES.

Results from the chemical analyses and density determinations are summarized in Table 1. The chemical composition of labradorite was tentatively established as $\left(\mathrm{Na}_{0.29} \mathrm{Ca}_{0.50} \mathrm{Mg}_{0.17}\right)\left(\mathrm{Al}_{1.38} \mathrm{Fe}_{0.12} \mathrm{Si}_{2.46}\right) \mathrm{O}_{8}$, where $\mathrm{Mg}$ and $\mathrm{Fe}$ substitute some $\mathrm{Ca}$ and $\mathrm{Al}$ respectively. The chemical formula of the magnetite specimen is that of ideal magnetite, $\mathrm{Fe}_{3} \mathrm{O}_{4}$, with some noticeable impurities $(\mathrm{Mg}, \mathrm{Si}, \mathrm{Al})$, probably associated with silicate minerals that were of amorphous character or were below the detection limit of the XRD method.

\section{Method}

After visual inspection of the mineral specimens with the help from a geologist, impurities were removed, based on differences in color, texture, structure, hardness, etc. The minerals were then sawed into parallelepipeds of $3 \times 3 \mathrm{~cm}$ basis, and about $5 \mathrm{~cm}$ long, for a first BET surface area determination (see below). Thereafter, the pieces were mechanically crushed, first roughly in a plastic bag, then in an agate mortar for finer particles. The crushed material was sieved (Retsch stainless steel sieves, $200 \mathrm{~mm} \varnothing \times 250$ and/or $500 \mathrm{~mm}$ ) on a shaking machine, first vigorously for 20-30 min, then at a low speed for one hour. Five fractions were collected: $0.075-0.125 ; 0.125-0.25 ; 0.25-0.5 ; 0.5-1$; $1-2 ; 2-4$ and $4-8 \mathrm{~mm}$. The collected fractions were then 
washed with $95 \%$ ethanol until ultrafine particles had been removed as indicated by the clarity of the ethanol.

BET surface area determinations [6] were made on different particle size fractions, using a gas adsorption process. The BET method is based upon the phenomenon of physical adsorption of gases on the external and internal surfaces of a porous material. This material is surrounded by and in equilibrium with a certain gas, at a temperature $T$ and a relative vapor pressure $p / p_{0}$, and physically adsorbs certain amount of gas. The amount of adsorbed gas is dependent on its relative vapor pressure and is proportional to the total external and internal surface of the material [21]. The accuracy of the instrument (ASAP 2020, Micromeritics) was assured by analyses of standard samples of alumina (pnr: 004-16816-00, lot nr: 152624-5, Micromeritics) and carbon black (pnr: 004-16833-00, lot nr: D-4, Micromeritics) with specific surface area of $0.27 \pm 0.03 \mathrm{~m}^{2} / \mathrm{g}(\mathrm{Kr})$, $0.28 \pm 0.03 \mathrm{~m}^{2} / \mathrm{g}\left(\mathrm{N}_{2}\right)$ and $24.1 \mathrm{~m}^{2} / \mathrm{g}$ (not gas-specific), respectively, with obtained values agreeing within the error limits to the standard values.

Before surface area determinations, the samples need to be dried under vacuum. In order to preserve the minerals from any surface modification, the degassing was made at room temperature. Degassing lasted one week for the centimeter-sized pieces, and $25 \mathrm{~h}$ for the crushed material. Some measurements have been made after a degassing time of only $10 \mathrm{~h}$ on the largest particle size fractions: $4-8$ and $2-4 \mathrm{~mm}$ for both minerals. The results were consistent with the ones obtained after $25 \mathrm{~h}$, thus confirming that the degassing time was sufficient. The degassing time of $25 \mathrm{~h}$ was chosen to reduce uncertainty. Measurements were mainly done using $\mathrm{Kr}$ as the absorbant and a ten point isotherm, with relative pressures varying from $p / p_{0}=0.05$ to 0.20 . A few comparative measurements were also done using $\mathrm{N}_{2}$ as the adsorbant gas, otherwise using an identical procedure as with the $\mathrm{Kr}$ gas.

\section{Results and discussion}

\subsection{Effect of analytical gas on the observed BET area}

Fig. 1 shows the results of replicate BET area determinations performed on labradorite and magnetite samples from the $0.075-0.125$ and $1-2 \mathrm{~mm}$ size fractions using $\mathrm{Kr}$ and $\mathrm{N}_{2}$ gas. Error bars in the figure indicate the analytical error in an individual determination. In Fig. 1, the line indicates identical results from analysis using the two different gases. For specific surface areas larger than $0.05 \mathrm{~m}^{2} \mathrm{~g}^{-1}$ the proximity of data points to the line indicates that for both magnetite and labradorite similar BET areas are obtained by analyses using the two different gases. At lower specific surface area, the data scatter more, and are slightly spread above the line (higher values obtained from $\mathrm{N}_{2}$ than from $\mathrm{Kr}$ measurements), probably reflecting the approach of the analytical limit of the instrument using $\mathrm{N}_{2}$ gas $\left(\sim 0.01 \mathrm{~m}^{2} / \mathrm{g}\right)$.

The uncertainty in an individual determination was $0.0001-0.0011 \mathrm{~m}^{2} / \mathrm{g}$, the standard deviation between replicate determinations was usually considerably larger $\left(0.0001-0.0063 \mathrm{~m}^{2} / \mathrm{g}\right)$. From Fig. 1, we note that both the uncertainty in an individual determination and the standard deviation between replicate determinations were smaller for

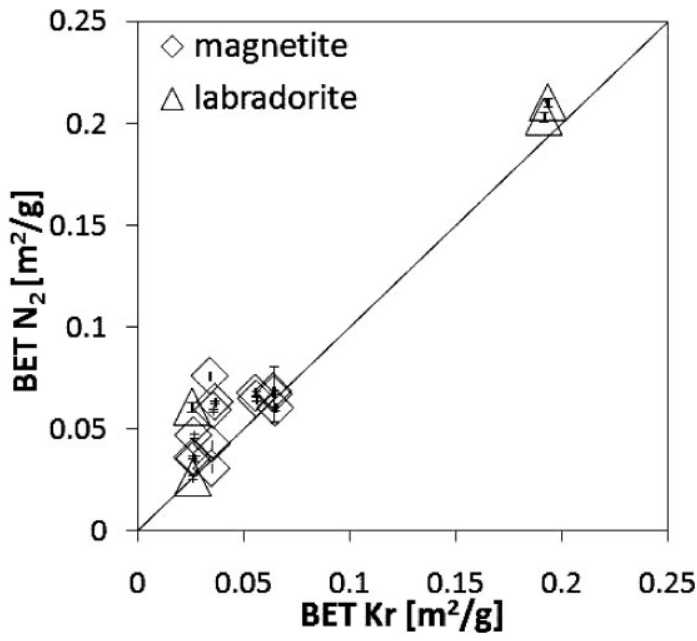

Fig. 1. Specific surface area as obtained from nitrogen $\left(\mathrm{N}_{2}\right)$ gas adsorption $\left[\mathrm{m}^{2} / \mathrm{g}\right]$ vs. values obtained using krypton $(\mathrm{Kr})$ gas adsorption $\left[\mathrm{m}^{2} \mathrm{~g}^{-1}\right]$ for labradorite $(\Delta)$ and magnetite $(\diamond)$ from size fractions $0.075-0.125$ and $1-2 \mathrm{~mm}$. The line represents perfect match between measurements using the two analytical gases. Error bars represent the analytical uncertainty in an individual determination expressed as one standard deviation. Note that for $\mathrm{Kr}$, the standard deviation is too small to be visible on the plot.

krypton than for nitrogen. Based on this and also the lower detection limit of krypton $\left(\sim 0.0004 \mathrm{~m}^{2} / \mathrm{g}\right.$, the lowest value that could be measured), we conclude that it is preferable to use krypton as adsorbing gas for the experiments, although similar results were obtained between the two gases.

\subsection{BET surface area of labradorite and magnetite}

Fig. 2a shows experimentally determined $\rho \mathrm{SSA}_{\text {tot }}\left[\mathrm{m}^{2} \mathrm{~m}^{-3}\right]$ as a function of the inverse of the representative particle radius for different particle fractions of labradorite and magnetite, as determined using $\mathrm{Kr}$ gas. Fig. $2 \mathrm{~b}$ represents a part of the same data set plotted for large particles only $\left(R^{-1}\right.$ up to $5 \mathrm{~mm}^{-1}$ ) for clarity. For both minerals, the trends observed in Fig. 2a show an increase of the surface area as the particle size decreases. Comparing the two minerals, the surface area values for large, not crushed pieces are quite similar $(0.0027$ and $0.0022 \mathrm{~m}^{2} \mathrm{~g}^{-1}$ for labradorite and magnetite, respectively, the data appear in the lower left corner in Fig. 2b). For the crushed material, magnetite has a larger specific surface area than labradorite for the large particle sizes; for the size fractions $2-4 \mathrm{~mm}$ to $0.25-0.50 \mathrm{~mm}$, the specific surface area $\left[\mathrm{m}^{2} \mathrm{~m}^{-3}\right]$ for magnetite is about two times that of labradorite. The fraction $0.125-0.250 \mathrm{~mm}$ presents similar surface area for both minerals. For the smallest fraction, however, labradorite shows a larger surface area than magnetite (Fig. 2a).

\subsection{Particle size dependency of the BET area}

For labradorite, a linear relationship between the specific surface area and the inverse of the particle size was found for particles sized 1-2 $\mathrm{mm}$ and smaller, as predicted from Eq. (6b) (Fig. 2a). A similar behavior was observed for sanidine and chlorite, by Dubois et al. [12]. In a linear regression of Eq. (6b) to experimental data of labradorite, the fitting parameters were the roughness factor $\lambda=8$ and the entity 

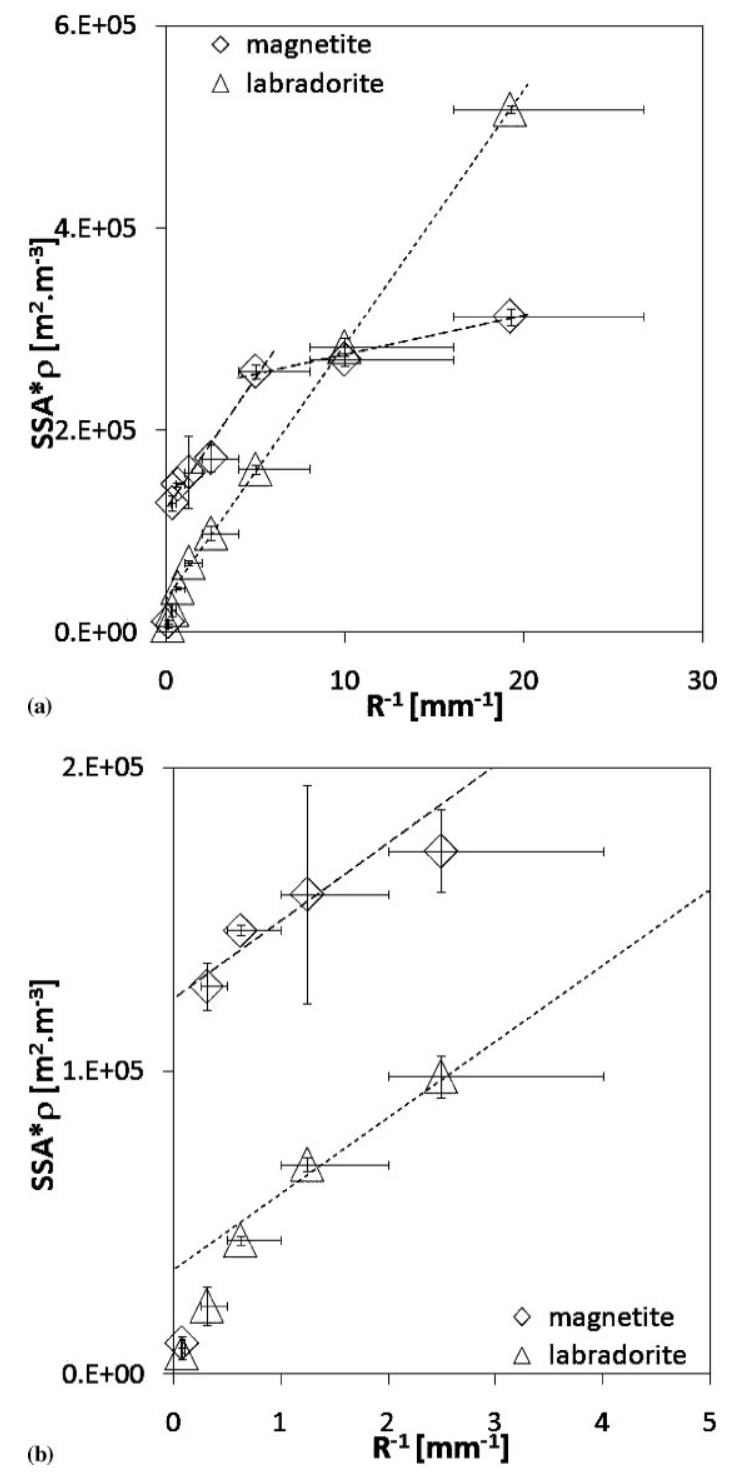

Fig. 2. BET surface area $\left(\rho \mathrm{SSA}_{\mathrm{tot}}\left[\mathrm{m}^{-1}\right]\right)$ as function of the inverse of the representative particle radius $\left[\mathrm{mm}^{-1}\right]$, for magnetite $(\diamond)$ and labradorite $(\Delta)$, using $\mathrm{Kr}$ gas adsorption. The vertical error bars represent three standard deviations of replicate BET area determinations. The horizontal error bars represent the upper and lower cut-off of the particle size, and is thus not associated with an experimental uncertainty. Broken lines show linear regression of Eq. (6b) to data (see text). (a) Data for the entire particle size range studied; (b) data for particles larger than $0.25 \mathrm{~mm}$ (subset of data in Fig. $2 \mathrm{a} ; R^{-1}$ up to $5 \mathrm{~mm}^{-1}$ ).

$\rho\left(a_{\mathrm{r}}+a_{\mathrm{dist}}\right) 36 \times 10^{3} \mathrm{~m}^{-1}$. A negative deviation, not observed for sanidine [12] from the linear trend is observed as the particle size increases (i.e. as $1 / R$ decreases, Fig. $2 b$ ) for labradorite, just as proposed by Eq. (6c), indicating that the disturbed zone to a lesser degree contributes to the measured specific surface area of these samples.

For magnetite two linear regions can be observed. A similar behavior was observed for chlorite, a sheet silicate [12]. A linear regression of Eq. (6b) to the data for the larger particles of magnetite, from the fractions $0.25-0.50 \mathrm{~mm}$ to $4-8 \mathrm{~mm}$, yields a roughness factor $\lambda=8$. This is in agreement with results obtained for other types of rocks [8,22], with sanidine [12] and the labradorite in this study. However, for the small particle sizes, from the fractions $0.075-0.125$ to $0.25-0.5 \mathrm{~mm}$, a roughness factor $\lambda=1-1.5$ is obtained, implying comparably smooth particles. For the smaller particles of magnetite, the apparent $\rho\left(a_{\mathrm{r}}+a_{\mathrm{dist}}\right)$ is $24 \times 10^{4} \mathrm{~m}^{-1}$ whereas for the larger particles it is $12 \times 10^{4} \mathrm{~m}^{-1}$ (compare Fig. 2).

An explanation to the observed complex dependence of BET surface area of magnetite on particle size may be that crushing into larger particles creates rougher particles with a somewhat lower surface area of the disturbed zone, whereas crushing into smaller particles creates smoother particles with a more disturbed or larger extent of the mechanically affected zone. A disturbed zone with variable surface area would alternatively also comply with the experimental observations, and could be included into the model by modification of Eq. (6). Another explanation may be a non-spherical geometry of the crystalline grains. This has been observed for magnetite in other studies [23]. Such a non-spherical shape would affect Eq. (6), see for example [12] for modifications for a parallelepiped shape. However, uniform particles between different particle sizes would result in a constant slope of the BETsurface area with the inverse of the particle size. Possibly, different distributions of the particle sizes within an experimental size fraction could also affect the representative particle size, thereby affecting the analysis carried out here. Further investigations are needed in order to fully understand the observed behavior of magnetite BET surface area.

\subsection{Intrinsic, internal surface areas}

Extrapolation of the linear relation between specific surface area and the inverse of the particle size to infinite particle size (i.e. intact material) has in the literature been proposed as a means of estimating the internal surface area dominating the specific surface area of larger pieces. However, as pointed out by André et al. [8] and shown in Eq. (6b), this extrapolation yields the quantity $\left(a_{\mathrm{r}}+a_{\text {dist }}\right)$, with a possible considerable contribution of the properties of the disturbed zone created during the mechanical treatment of the samples. Here, we used determinations of the specific surface area of centimeter sized pieces, with total specific surface areas being comparatively less affected by a disturbed zone, as a second estimate of the intrinsic, internal surface area.

We note that the extrapolated surface areas from the crushed fractions are 5 to 22 times larger than those obtained by determinations on the large pieces. These results are in line with those of André et al. [8], who found ratios of 1.3-12 for different granite samples. We furthermore note that the surface area of the large mineral pieces are just 2$4 \%$ of that of the particle size fraction $0.075-0.125 \mathrm{~mm}$, which is representative of that employed in many radionuclide sorption experiments using crushed rock or mineral samples. This implies that the majority of the surface area in such experiments is associated with fresh mineral surfaces, not originally present, and possibly with different sorption properties from the large sample.

\subsection{Comparison to literature data}

The experimentally obtained specific surface areas in this study are low compared to the data found in the literature (Figs. 3 and 4, for magnetite and labradorite respectively). 


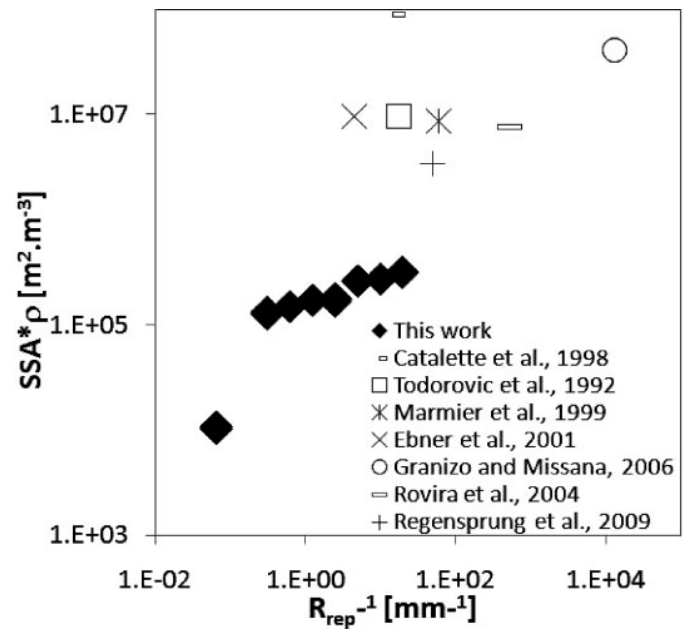

Fig. 3. Specific surface area $\left(\rho \mathrm{SSA}_{\text {tot }}\left[\mathrm{m}^{-1}\right]\right)$ as function of the inverse of the particle size $\left[\mathrm{mm}^{-1}\right]$ for magnetite (this study) compared with data taken from the literature. N.B. Logarithmic scales.

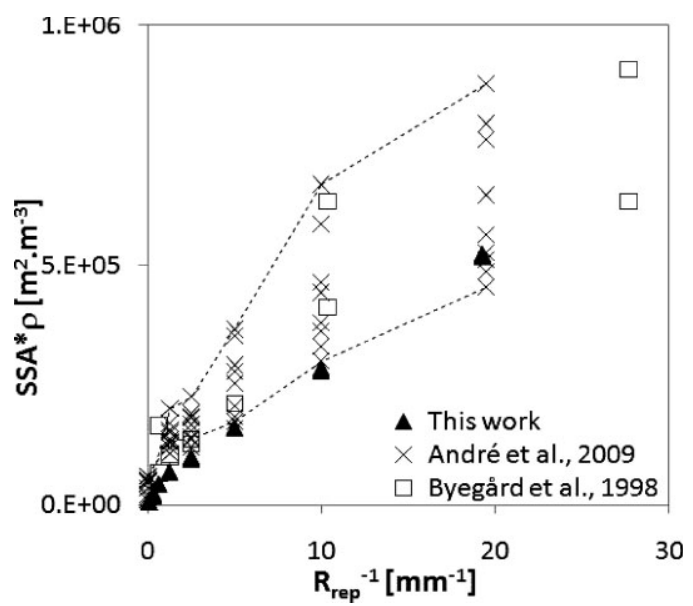

Fig. 4. Specific surface area $\left(\rho \mathrm{SSA}_{\text {tot }}\left[\mathrm{m}^{-1}\right]\right)$ as function of the inverse of the particle size $\left[\mathrm{mm}^{-1}\right]$ for labradorite (this study) and for granite (André et al., [7] ×; Byegård et al., [4] $\square$ ). The dotted lines connect data for two of the granitic samples investigated by André et al. (2009).

In this comparison, it should be noted that mineral samples may be very different between different studies, although the same type or group of mineral has been used. All of the studies in the literature presented here used nitrogen as adsorbing gas for their BET determinations. However, as shown above, the use nitrogen and krypton gas gave very similar results in our study, thereby indicating that the difference in analytical gas is not the cause of the observed difference in surface area. It should be noted that Fig. 3 show data that are not completely comparable. Catalette et al. [17] and Rovira et al. [19], used particle size fractions that were partially open $(<180 \mu \mathrm{m}$ and $<5 \mu \mathrm{m}$, respectively) meaning that there may be a large proportion of fine particles in these samples. Marmier et al. [18] and Ebner et al. [24] gave only the mean particle size, and not the limits of the size fraction. Thus the size fractions those authors worked on are not well defined in the cited references, which makes the comparison with our results difficult. Granizo et al. [20] worked on much smaller particle sizes than in this work.

Considering only references where particle sizes are well defined and comparable to those used in this work, our ex-
Table 2. Specific surface area $\left[\mathrm{m}^{2} \mathrm{~g}^{-1}\right]$ for large pieces and ratio [unitless] of extrapolated to experimentally determined value.

\begin{tabular}{lcc}
\hline & Magnetite & Labradorite \\
\hline $\begin{array}{l}\text { Experimental - } \\
\text { large piece }\end{array}$ & $0.0022 \pm 0.0001$ & $0.0026 \pm 0.0002$ \\
$\begin{array}{l}\text { Extrapolated - } \\
\text { small particles }\end{array}$ & $0.0486 \pm 0.0015$ & $0.0133 \pm 0.0022$ \\
$\begin{array}{l}\text { Extrapolated - } \\
\text { large particles }\end{array}$ & $0.0254 \pm 0.0015$ & \\
$\begin{array}{l}\text { Ratio (extrapolated/ } \\
\text { experimental) }\end{array}$ & $11-22$ & 4.9 \\
\hline
\end{tabular}

perimental data are still about 30 times lower than Todorovic et al. [25], and 13 times lower than those of Regenspurg et al. [26]. Both Todorovic et al. [25] and Regenspurg et al. [26]used natural magnetite in their experiments, just as in this study, but from different locations than the specimen used here. It is not unusual to find that samples of the same mineral differ of about one order of magnitude in their surface area, for example as observed for two chlorites [27], sampled at different locations in Sweden, but otherwise treated exactly the same way. Considering the natural variability in properties between different natural specimens of the same mineral, we find the observed surface area of the magnetite in this study in fair agreement with literature data of other specimen.

No data of specific surface area for labradorite has been found in the literature. However, as plagioclase is one of the main components in granite [28] a comparison was made with data obtained for granite by Byegård et al. [4] and André et al. [8], as shown in Fig. 4. André et al. [8] worked with granite, sampled at Forsmark and Laxemar, on the Swedish East coast. Byegård et al. [4] worked with Äspö Diorite and Fined Grained Granodiorite, also from the Swedish East coast. The surface area values for labradorite obtained in this study were in good agreement with data from both works, although experimental data for labradorite are in the lower range of the data for granite. The specific surface area of labradorite was also similar to that observed for sanidine by Dubois et al. [12] (note that their $b$ equals $2 R$; in this study, not shown in Fig. 4).

\section{Conclusions}

The specific surface area has been determined with $\mathrm{Kr}$ and $\mathrm{N}_{2}$ gas adsorption, using the BET model, for seven particle size fractions, including centimeter-sized samples, of two pure minerals, labradorite and magnetite. Results obtained from $\mathrm{Kr}$ and $\mathrm{N}_{2}$ gas adsorption were similar, with somewhat better precision from $\mathrm{Kr}$ determinations. For the labradorite, the specific surface area was similar to literature data for similarly sized particles of granite and sanidine. As plagioclase is one of the main components of granitic material, it seems that the behavior of the surface areas for labradorite mineral and for granitic rock appear to be very similar, during the process of crushing the material to different size fractions.

For our natural magnetite, the specific surface area was a factor 13-30 lower compared to literature data of other 
natural magnetite samples with well defined particle sizes. We suggest that such a comparably small difference in specific surface area between different samples of the same particle size fraction may be related to differences in particle geometry, surface smoothness or internal surface area between the mineral specimens.

Both labradorite and magnetite show decreasing surface area with increasing particle size for crushed material. Experimental data for labradorite followed the model proposed by André et al. [8]. This model assumes spherical (or cubic) particles with constant but different specific internal surface area between the undisturbed part of the particle and a mechanically disturbed zone. In contrast, the experimental data for magnetite showed that the model could not be fitted to the data for the complete range of particle size fractions studied. Separate fits could be obtained when dividing the size fractions into two groups: one group with relatively large particles and one group with the fine particles. This behavior needs to be further studied, and we propose that it may be related to an internal specific area (i.e. the porosity) or surface roughness that is not constant over the particle sizes studied, or a particle geometry that greatly deviates from spherical or cubic. The particle size distribution within the fractions may also be a factor that can contribute to the observed phenomena and would be worthwhile to investigate.

The experimentally determined specific surface area of the centimeter-sized samples for both the minerals were considerably lower than the values obtained from linear extrapolation of results for smaller particle sizes. This result is in agreement with the results obtained by André et al. [5,8] for granite samples, and indicates that the mechanical treatment of samples creates new, internal surfaces (see also [12]). With relevance for the determination of radionuclide sorption properties of rocks and minerals, this indicates that the radionuclide sorption for intact material may be greatly overestimated if it is based on extrapolation of laboratory experiments on crushed material (see also $[12,29])$. This furthermore suggests that sorption results of experiments on crushed material may be dominated by the properties of fresh surfaces, not originally present in the rock or mineral.

Acknowledgment. We acknowledge Prof. Rob Hellingwerf, from The Swedish School of Mining and Metallurgy, Bergsskolan, Filipstad, Sweden, for providing the labradorite, and Prof. Ulf Hålenius, from the Swedish Museum of Natural History, Stockholm, Sweden, for providing the magnetite sample. We thank Dr. Eva-Lena Tullborg, from Terralogica, and Dr. Henrik Drake for geologic help, as well as Ali Firoozan from the Department of Earth Sciences, Gothenburg University, Gothenburg, for his help to clean the minerals. Thanks to Prof. Vratislav Langer, from the Environmental Inorganic Chemistry Department, Chalmers University of Technology, Gothenburg, Sweden, for his help with the XRD analyses. We thank two anonymous reviewers for valuable comments on the manuscript. This work was financed by the Swedish Nuclear Fuel and Waste Management Co, SKB, Stockholm, Sweden.

\section{References}

1. Spadaro, J. V., Langlois, L., Hamilton, B.: Greenhouse Gas Emissions of Electricity Chains: Assessing the Difference. IAEA Bulletin, 42/2/2000. Vienna, Austria (2000).
2. Pachauri, R. K., Reisinger, A.: Climate change 2007: synthesis report. Contribution of Working Groups I, II and III to the Fourth Assessment Report of the Intergovernmental Panel on Climate Change 2007, IPCC Geneva Switzerland (2007).

3. Inch, K. J., Killey, R. W. D.: Surface area and radionuclide sorption in contaminated aquifers. Water Pollut. Res. J. Canada 22(1), 85-98 (1987).

4. Byegård, J., Johansson, H., Skålberg, M.: The interaction of sorbing and non-sorbing tracers with different Äspö rock types - Sorption and diffusion experiments in the laboratory scale. Swedish Nuclear Fuel and Waste Management Co, SKB Technical Report TR-98-18 Stockholm, Sweden (1998).

5. André M., Malmstrom, M. E., Neretnieks, I.: Measuring sorption coefficients and BET surface areas on intact drillcore and crushed granite samples. Radiochim. Acta 96(9-11), 673-677 (2008).

6. Brunauer, S., Emmet, P. H., Teller, E.: Adsorption of gases in multimolecular layers. J. Am. Chem. Soc. 60(2), 309-319 (1938).

7. Skagius, K., Svedberg, G., Neretnieks, I.: A study of strontium and cesium sorption on granite. Nucl. Technol. 59, 302-313 (1982).

8. André, M., Malmström, M. E., Neretnieks, I.: Specific surface area measurements on intact drillcores and evaluation of extrapolation methods for rock matrix surfaces. J. Contam. Hydrol. 110(1), 1-8 (2009).

9. Winberg, A., Hermanson, J., Tullborg, E. L., Staub, I.: Äspö Hard Rock Laboratory - Long-Term Diffusion Experiments - Structural model of the LTDE site and detailed description of the characteristics of the experimental volume including target structure and intact rock section. Swedish Nuclear Fuel and Waste Management Co, SKB International Progress Report IPR-03-51 Stockholm, Sweden (2003).

10. Tsang, C.-F., Bernier, F., Davies, C.: Geohydromechanical processes in the Excavation Damaged Zones in crystalline rock, rock salt, and indurated and plastic clays - in the context of radioactive waste disposal. Int. J. Rock Mech. Mining Sci. 42(1), 109-125 (2005).

11. Bradbury, M. H., Baeyens, B.: $\mathrm{N}_{2}$-BET surface areameasurements on crushed and intact minerals and rocks: a proposal for estamating sorption transfer factors. Radioact. Waste Manage. Dispos. 122, 250-253 (1997).

12. Dubois, I., Holgersson, S., Allard, S., Malmstrom, M. E.: Correlation between particle size and surface area for chlorite and K-feldspar. In: Water-Rock Interaction. (Torres-Alvarado, B., ed.) Taylor \& Francis Group, London (2010), pp. 717-720.

13. André, M., Malmström, M. E., Neretnieks, I.: Specific surface area measurements on intact drillcores and evaluation of extrapolation methods for rock matrix surfaces. J. Contam. Hydrol. 110(1), 1-8 (2009b).

14. SKB: Äspö Hard Rock Laboratory - Annual Report 2008. Swedish Nuclear Fuel and Waste Management Co, SKB Technical Report TR-09-10 Stockholm, Sweden (2009).

15. Asci, Y. A., Nurbas, M., Acikel, Y. S.: A comparative study for the sorption of $\mathrm{Cd}(\mathrm{II})$ by K-feldspar and sepiolite as soil components, and the recovery of $\mathrm{Cd}(\mathrm{II})$ using rhamnolipid biosurfactant. J. Environ. Manage. 88(3), 383-392 (2008).

16. Berglund, J., Curtis, P., Eliasson, T., Olsson, T., Starzec, P., Tullborg, E. L.: Äspö Hard Rock Laboratory - Update of the geological model 2002. Swedish Nuclear Fuel and Waste Management Co, SKB International Progress Report IPR-03-34 Stockholm, Sweden (2003).

17. Catalette, H., Dumonceau, J., Ollar, P.: Sorption of cesium, barium and europium on magnetite. J. Contam. Hydrol. 35(1-3), 151-159 (1998).

18. Marmier, N., Delisee, A., Fromage, F.: Surface complexation modeling of $\mathrm{Yb}(\mathrm{III}), \mathrm{Ni}(\mathrm{II})$, and $\mathrm{Cs}(\mathrm{I})$ sorption on magnetite. J. Colloid Interface Sci. 211(1), 54-60 (1999).

19. Rovira, M., De Pablo, J., Casas, I., Giménez, J., Clarens, F.: Sorption of cesium on commercial magnetite with low silica content: experimental and modeling. Mater. Res. Soc. Symp. Proc. 807, 677-682 (2004).

20. Granizo, N., Missana, T.: Mechanisms of cesium sorption onto magnetite. Radiochim. Acta 94(9-11), 671-677 (2006).

21. Fagerlund, G.: Determination of specific surface by the BET method. Matér. Construct. 6(3), 239-245 (1973). 
22. Anbeek, C.: Surface roughness of minerals and implications for dissolution studies. Geochim. Cosmochim. Acta 56, 1461-1469 (1992).

23. Gregoire, V., Darrozes, J., Gaillot, P., Nedelec, A.: Magnetite grain shape fabric and distribution anisotropy vs rock magnetic fabric: a three-dimensional case study. J. Struct. Geol. 20(7), 937-944 (1998).

24. Ebner, A. D., Ritter, J. A., Navratil, J. D.: Adsorption of cesium, strontium, and cobalt ions on magnetite and a magnetite-silica composite. Ind. Eng. Chem. Res. 40(7), 1615-1623 (2001).

25. Todorovic, M., Milonjic, S. K., Comor, J. J., Gal, I. J.: Adsorption of radioactive ions $\mathrm{Cs}-137^{+}, \mathrm{Sr}-85^{2+}$, and $\mathrm{Co}-60^{2+}$ on natural magnetite and hematite. Sep. Sci. Technol. 27(5), 671-679 (1992).
26. Regenspurg, S., Malmstrom, M. E.: Experimental quantification of contaminant (im)mobilization kinetics - uranyl sorption/desorption from iron oxides. In preparation (2009).

27. Zazzi, Å., Malmstrom, M. E., Wold, S.: Dissolution rate and stoichiometry of two different chlorites as a function of $\mathrm{pH}$. In preparation (2009).

28. Drake, H., Sandström, B., Tullborg, E. L.: Mineralogy and geochemistry of rocks and fracture fillings from Forsmark and Oskarshamn: compilation of data for SR-Can. Swedish Nuclear Fuel and Waste Management Co, SKB Report R-06-109 Stockholm, Sweden (2006)

29. André, M., Malmstrom, M. E., Neretnieks, I.: Determination of sorption properties of intact rock samples: new methods based on electromigration. J. Contam. Hydrol. 103(3-4), 71-81 (2009). 